\title{
UNA FILOSOFÍA DEL DERECHO PARA EL MUNDO LATINO. OTRA VUELTA DE TUERCA*
}

Manuel Atienza

Universidad de Alicante

RESUMEN. El autor desarrolla los planteamientos que había formulado previamente en una especie de Manifiesto en favor de una filosofía del derecho para el mundo latino, que se publicó en el número 30 de la revista (2007), y subraya de qué manera se conecta con una visión argumentativa del derecho.

Palabras clave: Filosofía del derecho, mundo latino, postpositivismo.

\section{A Philosophy of Law for the Latin World. A step forward}

ABSTRACT. The author elaborates on some theses previously formulated in a kind of Manifesto for a Philosophy of law for the latin world -reliesed in this Journal, issue 30, year 2007. The connection between this project and an argumentative approach to the law is specifically highlighten.

Keywords: Philosophy of Law, latin world, postpositivism.

* Fecha de recepción: 15 de mayo de 2014. Fecha de aceptación: 2 de julio de 2014. 
1.

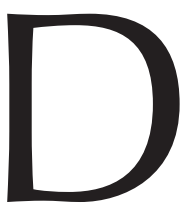

esde hace algunos años he estado dándole vueltas a la idea de si (y cómo) se podría proponer algo así como un modelo de elaboración de la filosofía del derecho para el mundo latino. Incluyo en el mundo latino, obviamente, a los países latinoamericanos, pero también a los países latinos de Europa, de manera que el concepto de «mundo latino» es más amplio que el de Hispanoamérica o el de Iberoamérica. De lo que se trata con ello es de incorporar a otros países europeos, además de España y Portugal, y, en particular, a Italia. Y la razón es bastante obvia: los estudios de filosofía del derecho han tenido un gran desarrollo en este país en los últimos tiempos. Para mostrar — si es que fuera necesario hacerlo_ - hasta qué punto es así, bastará con mencionar el nombre de Norberto BOBBIO, el padre de la actual iusfilosofía italiana, pero responsable también en gran medida de mucho de lo que se ha hecho en España en las últimas décadas (desde la introducción de sus ideas iusfilosóficas en los años sesenta del siglo XX por Elías DíAz) y cuya obra ha tenido y sigue teniendo igualmente una considerable influencia en muchos países latinoamericanos.

Pues bien, esa idea de una filosofía del derecho para el mundo latino la he ido modelando en varios escritos de los últimos años, pero en realidad creo que siempre ha estado en el trasfondo de todo mi trabajo intelectual: desde que comencé mi carrera académica con una tesis sobre la filosofía del derecho en Argentina (completada en 1976). En el año 2007 (ATIENZA, 2008), en el contexto de una discusión con Eugenio Bulygin sobre el positivismo jurídico, propuse un Manifiesto (en forma de decálogo), en el que trataba de sugerir (después de defender la tesis de que el positivismo jurídico no podía considerarse como una concepción aceptable del derecho) cómo habría que construir una filosofía (una teoría) del derecho con la vista puesta en los países latinos de Europa y de América. Me pareció también que las ideas expresadas en ese Manifiesto eran compatibles, no exactamente con ser marxista, pero sí con muchas ideas que se encuentran en esa tradición de pensamiento y que haríamos mal en abandonar sin más; es decir, en suprimir de lo que podría considerarse como el acervo cultural de un filósofo del derecho de nuestra época y de nuestros mundos. Así lo expresé en un texto de 2009 titulado Por qué leer a Marx hoy (ATIENZA, 2009a). Volví otra vez al tema al ocuparme de la filosofía del derecho en Argentina en los últimos tiempos (ATIENZA, 2009b), insistiendo siempre en que ese tipo de teoría que yo proponía no tendría que ser positivista, debería comprometerse con un objetivismo mínimo en materia valorativa ( filosófico en uno de los significados de esta última expresión, y esforzarse por insertar esa teoría o filosofía del derecho en la práctica jurídica: en las diversas prácticas jurídicas. Y, finalmente, volví a ocuparme de esa cuestión en 2012, en mi contribución para el primer número de la nueva época de la Rivista di filosofía del diritto, para el cual, la dirección de la misma invitó a una serie de iusfilósofos a ofrecer una contestación a la pregunta de «¿Qué filosofía del derecho?». En ese trabajo (ATIENZA, 2012), partía de una discusión que había tenido lugar a propósito de un artículo de FERRAJOLI (2011) en el que este autor planteaba dos modelos de constitucionalismo: el garantista o normativo, el suyo; y el principialista o argumentativo, entre cuyos defensores me incluía. Los puntos a debatir eran estos tres: la conexión o separación entre el derecho 
y la moral; la contraposición entre las reglas y los principios; y la forma de entender la ponderación (en cuanto mecanismo argumentativo requerido por la aplicación de principios). Dicho de manera sintética, mi opinión venía a ser que la obra de FERRAJOLI (y no era ni mucho menos la primera vez que discutía con él en relación con estas cuestiones) cumple con algunas de las exigencias que yo trazaba en aquel Manifiesto, pero se aleja del mismo en dos aspectos de considerable relevancia: en su adhesión al positivismo jurídico (por mucho que insista en que el positivismo jurídico que él defiende está bastante alejado de lo que él acostumbra a llamar «paleopositivismo») y en su escepticismo (o, como él prefiere denominarlo, «no-cognoscitivismo») en materia moral.

Pero permítanme que les lea aquel Manifiesto, antes de seguir adelante y cumplir con lo que sugiere el subtítulo de mi conferencia: Otra vuelta de tuerca.

1. Si el derecho — como alguna vez se ha escrito— es «una gran acción colectiva que transcurre en el tiempo», una práctica social, entonces la teoría del derecho tiene, de alguna manera, que formar parte de esa práctica. Una consecuencia de ello es que el teórico del derecho no puede ser ajeno a los valores de esa práctica, ni puede tampoco concebir su participación en la misma en términos puramente individuales. Lo que debería guiar nuestro trabajo, en definitiva, no es el afán de originalidad, sino de participar cooperativamente con otros en la mejora de esa práctica.

2. La elaboración de una teoría del derecho completamente general, válida para cualquier sistema jurídico, es una empresa de valor limitado. Pero, además, no es nada obvio que la teoría jurídica al uso, el paradigma anglo-americano dominante (positivista o no), sea verdaderamente general. Por eso, ante el riesgo cierto de que la globalización en la teoría del derecho responda más bien a lo que se ha llamado la «globalización de un localismo», podría ser de interés desarrollar teorías del derecho — digamos— «regionales», de acuerdo con los diversos círculos de cultura hoy existentes. El multilateralismo parece una estrategia deseable, y no sólo en el ámbito de la política internacional.

3. Los países latinos, de Europa y de América, constituyen uno de esos círculos culturales. Aunque con niveles de desarrollo económico, político, científico, tecnológico, etc. diferentes, esos países son sumamente afines desde el punto de vista de sus sistemas jurídicos y de sus lenguas, poseen una rica tradición de pensamiento jurídico, y en todos ellos el Estado constitucional opera como un ideal regulativo para el desarrollo del derecho y de la cultura jurídica. En muchos de esos países la filosofía del derecho ocupa hoy un lugar académicamente destacado, lo que explica que exista un buen número de cultivadores de la disciplina con un alto nivel de competencia «técnica». ¿Cómo explicar entonces que la producción iusfilosófica se limite en buena medida a comentar o discutir ideas y teorías surgidas en otros ámbitos culturales y destinadas también muchas veces a tratar con problemas característicos de esos otros ámbitos?

4. Lo anterior no es una invitación al localismo en la teoría del derecho, sino a distinguir entre lo pura o fundamentalmente local y lo que tiene —o puede tener- un valor genuinamente general o universal (en relación, al menos, con el universo del Estado constitucional). Las teorías iusfilosóficas de ámbito regional podrían configurar una útil mediación ente lo local y lo universal y contribuir así a una globalización más equilibrada en la teoría del derecho.

5. La filosofía del derecho no es un género retórico, pero una forma equivocada de practicar la teoría jurídica consiste en desentenderse de quiénes son los destinatarios de los escritos iusfilosóficos y de quiénes pueden hacer uso de las ideas que se encuentran en ellos. Quizá no tenga sentido producir obras destinadas únicamente a otros filósofos del derecho, y menos aún cuando sus destinatarios directos parecerían ser intelectuales a los que todo lo que se genera fuera de su ámbito cultural les es ajeno. 
6. Otro error, que frecuentemente va de la mano del anterior, es el de olvidar que una teoría del derecho sólo merece la pena si se ocupa de problemas relevantes y que esa relevancia viene fijada por los intereses de la comunidad jurídica ampliamente entendida. Además de algún otro factor de carácter exógeno, no es absurdo pensar que la falta de atención a los problemas y a los destinatarios puede constituir la principal explicación de la insatisfactoria situación de la filosofía del derecho en los países latinos: un (al menos en muchos casos) alto nivel de sofisticación técnica y una (en general) escasa influencia en la cultura jurídica y en la práctica del derecho de sus respectivos países.

7. Un modelo de teoría del derecho pragmáticamente útil y culturalmente viable en nuestros países bien podría consistir en combinar estos tres ingredientes: método analítico, objetivismo moral e implantación social. Cada uno de ellos está especialmente vinculado a una de las grandes concepciones del derecho bajo las cuales se suele clasificar, entre nosotros, a los filósofos del derecho: el positivismo jurídico, el iusnaturalismo y la teoría crítica del derecho.

8. Positivismo jurídico y filosofía analítica no son, obviamente, términos sinónimos pero, dada la estrecha vinculación existente entre ambos, es razonable considerar que el método analítico es uno de los aspectos más valiosos que el positivismo jurídico puede dejar como herencia a la cultura jurídica. Ese método suele cifrarse en el uso y aceptación de ciertas distinciones (por ejemplo, entre enunciados descriptivos y prescriptivos, o entre explicar y justificar) que, por lo demás, no deberían entenderse en un sentido rígido: entre lo descriptivo y lo prescriptivo pueden existir «puentes» y explicar una decisión puede contribuir notablemente a su justificación.

9. Algo parecido puede decirse de la relación entre el iusnaturalismo y el objetivismo moral y la unidad de la razón práctica, si bien la manera más adecuada de sostener estas dos últimas tesis no consiste en recurrir al derecho natural, sino a alguna forma de procedimentalismo o constructivismo moral. En todo caso, las dos principales razones para rechazar el no cognoscitivismo ético (y el relativismo, pero obviamente no como posición de ética descriptiva) son: 1) no permite reconstruir aspectos importantes de la práctica jurídica (en particular, de la justificación de las decisiones judiciales); 2) es autofrustrante. La alternativa debería ser un objetivismo moral (mínimo) que, frente al relativismo, defienda la tesis de que los juicios morales incorporan una pretensión de corrección y, frente al absolutismo, la de que los juicios morales (como los de los tribunales de última instancia) incorporan razones últimas (en el razonamiento práctico), pero abiertas a la crítica y, por tanto, falibles.

10. Los aspectos más valiosos de las teorías críticas del derecho giran en torno a la necesidad de insertar el derecho (y la teoría del derecho) en el medio social y plantearse su potencial de transformación social. Esa concepción (o una cierta manera de entenderla) muestra así la necesidad de que la teoría del derecho incorpore ciertas categorías que generalmente quedan fuera del análisis (conflicto, trabajo, poder, necesidad social), asuma el carácter histórico del derecho y de las categorías jurídicas y preste atención a los elementos desigualitarios e ideológicos del derecho (también de los derechos del Estado constitucional).

\section{2.}

Trataré ahora de desarrollar esos diez puntos teniendo en cuenta (incorporando) algunos aspectos presentes en los trabajos a los que antes hacía referencia y en algunos otros de los últimos tiempos. Muchos de esos escritos forman parte de polémicas con iusfilósofos del mundo latino que defienden posturas más o menos alejadas de la mía: Bulygin, Guastini, Comanducci, Chiassoni, Laporta, García Amado, Haba o FERRAJOLI. Y versan sobre temas tales como el positivismo jurídico, el constitucionalismo, la ponderación, el objetivismo moral, o la función de las teorías argumentativas del derecho. La tesis última que voy a defender aquí es que una filosofía del derecho 
que cumpla con los requisitos establecidos en ese Manifiesto significa hoy, fundamentalmente, una que se centre en la dimensión argumentativa del derecho. Veámoslo.

\section{1. ${ }^{1}$}

El autor de la frase «el derecho es una gran acción colectiva que transcurre en el tiempo» es Carlos NINO, pero algo muy semejante podría encontrarse en DWORKIN, en general en los autores que integran el paradigma constitucionalista, en los hermenéuticos y los que se consideran dentro de la tradición iusnaturalista (FULLER contrapuso al normativismo de un KELSEN o de un HART su visión del derecho como una empresa, una actividad, con la que tratan de lograrse determinadas finalidades), en los realistas jurídicos (particularmente los norteamericanos), etc. El que pueda ser aceptada por muy diversas concepciones del derecho no quiere decir, ni mucho menos, que se trate de una tesis trivial. No lo es cuando se considera a qué (a qué otra concepción del derecho) se opone, y qué consecuencias tiene.

Pues bien, se opone, hablando en términos generales, al positivismo normativista, esto es, a la que probablemente haya sido (sigue siendo) la concepción del derecho dominante en el mundo latino. Podría pensarse quizás que esto no es así (o no necesariamente) dado que, precisamente, una tesis esencial del positivismo (de cualquier tipo) es la de las fuentes sociales del derecho. Pero la idea de que el derecho es una práctica social expresa algo más: no sólo el carácter artificial, convencional si se quiere, del derecho, sino su dimensión valorativa, sin la cual la idea de práctica social se desvanecería. Por eso, no se considera la dimensión del derecho como práctica social cuando el mismo se reduce a un lenguaje (el lenguaje de los enunciados legislativos) y el papel de la teoría o de la filosofía del derecho al análisis de ese lenguaje. Como se sabe, esa es la tesis defendida por BOBBIO en un famosísimo trabajo de 1950 (BOBBIO, 1950) que se considera como el origen de la iusfilosofía analítica en Italia y que sigue funcionando como paradigma en muchos centros del mundo latino. BoBBIO, por cierto, cambió esa manera de entender el derecho y la teoría jurídica en trabajos posteriores [en alguno de los cuales parece haberse aproximado al realismo jurídico (en BOBBIO, 1980)], pero ese esquema inicial de Bobbio no ha perdido del todo su carácter programático. Así, en un trabajo reciente y significativamente titulado Manifesto di una filosofía analítica del diritto, Riccardo GUASTINI (2012) parte del «presupuesto ontológico-jurídico» de que «el derecho no es más que un lenguaje, un discurso: el conjunto de enunciados formulados por la autoridad normativa»; y de que «la filosofía del derecho sería, en consecuencia, un método consistente en el análisis lógico del lenguaje» (p. 52). Afirmaciones ambas que también parecerían valer para FERRAJOLI [piénsese en su monumental «Principia iuris» (FERRAJOLI, 2010)] y para muchos otros autores del mundo latino cuyas obras gozan de una considerable influencia.

Y las consecuencias teóricas y prácticas de asumir una u otra concepción son considerables. Pensemos, por ejemplo, en el tema de la interpretación. Para los iuspositivistas como GUASTINI (1990) o BULYGIN (1992) interpretar consiste simplemente en pasar de un enunciado (una disposición) a otro (a una norma: el enunciado interpreta-

\footnotetext{
${ }^{1}$ La numeración hace referencia a cada uno de los puntos del Manifiesto.
} 
do) lo que requiere de una regla semántica (un canon de interpretación). Por supuesto, la interpretación es vista también por estos autores como una operación importante en el derecho, pero según ellos no habría en ella nada de particular, simplemente porque lo único que estarían considerando (sobre todo en el caso de BuLYGIN) es el plano formal o lógico del derecho. Por razones parecidas, la interpretación no juega tampoco un papel muy importante en la obra de FERRAJOLI, al igual que ocurre en la de KELSEN. Sin embargo, las cosas son muy distintas para quien ve el derecho como una práctica social, pues desde esta última perspectiva la interpretación adquiere una importancia esencial: mediante la interpretación se trata de desarrollar los valores de esa práctica, sin salirse de la misma: interpretar no es inventar. No se puede, por ello, interpretar sin asumir un punto de vista interno a la práctica, esto es, sin aceptar los valores de la práctica; el propósito de la interpretación ha de ser el de desarrollar esos valores de una manera coherente. Y esto significa que no es posible tampoco establecer una separación estricta entre la labor de los teóricos generales del derecho, la de los dogmáticos o la de los operadores prácticos del derecho. La teoría jurídica, en definitiva, no puede ser puramente descriptiva y explicativa: es también, esencialmente, normativa: dirige la práctica y se integra con ella.

\section{2.}

Lo anterior no supone, naturalmente, negar que el derecho consista en un conjunto de enunciados, en un sistema normativo. Consiste en eso, pero no sólo en eso. O sea, la práctica social que es el derecho no puede entenderse sin la noción de sistema, de sistema normativo, pero incorpora también una dimensión valorativa. Dicho de otra manera: el derecho es una práctica autoritativa que pretende lograr ciertos valores. Y esa doble dimensión (autoritativa y valorativa) se traslada también al campo de la interpretación. Interpretar en el derecho es una actividad esencial (a diferencia de lo que ocurre por ejemplo en la moral), por el papel sobresaliente de la autoridad, pero se interpreta para satisfacer ciertos valores. Al interpretar se produce el paso de un enunciado (el enunciado a interpretar, la disposición) a otro (el enunciado interpretado, la norma), lo cual puede expresarse en una operación lógica, pero lo que guía la interpretación no puede ser otra cosa que valores, de manera que una teoría de la interpretación tiene que contener también, necesariamente, un elemento axiológico: una filosofía moral y política.

\section{3.}

Otra consecuencia importante de una u otra forma de concebir el derecho afecta precisamente a la idea misma de la filosofía del derecho para el mundo latino. Pues si uno parte de una concepción positivista del derecho como la que se acaba de señalar, entonces no parece que tenga sentido expresarse en esos términos. ¿En qué podría diferenciarse una filosofía del derecho para el mundo latino con respecto a la filosofía del derecho tout court? Mientras que las cosas no son ya así si se asume la otra concepción. O sea, si la filosofía del derecho se concibe como una reflexión a partir de nuestras 
prácticas jurídicas, entonces es posible pensar en una iusfilosofía más o menos diferenciada de otras, puesto que en la misma tendrían que traslucirse los rasgos peculiares de esas prácticas. Rasgos que, obviamente, desaparecen cuando el trabajo iusfilosófico se centra en (y se reduce a) operaciones tales como la de caracterizar el lenguaje prescriptivo frente al descriptivo, las normas de mandato frente a los permisos, las lagunas normativas frente a las axiológicas, etcétera.

\section{4 .}

Otra forma de expresar la anterior idea consistiría en afirmar que una concepción positivista del derecho tiene pretensiones exclusivamente cognoscitivas, aunque se trate de un conocimiento puramente formal del derecho. Mientras que para la concepción del derecho como una práctica social a las pretensiones cognoscitivas se añadiría otra (la fundamental) de carácter práctico o político. El filósofo del derecho no trataría exactamente o en lo esencial de alcanzar nuevos conocimientos (de buscar un tipo de originalidad como la que pudiera representar una nueva forma de caracterizar la diferencia entre las reglas y los principios o de entender la validez), sino más bien de elaborar conceptos que puedan contribuir a hacer avanzar la práctica.

\section{5 .}

Vista como práctica teórica, la filosofía del derecho es una actividad que requiere de ciertos elementos sin los que no podría existir una comunidad iusfilosófica. Así, quienes desarrollan la práctica tienen que compartir ciertas finalidades, aunque se trate de finalidades dadas en un plano más bien abstracto. Entre sus miembros tendría que darse cierto grado de conocimiento mutuo, es decir, tendrían que tomarse unos a otros en serio en cuanto interlocutores. Y hay un tipo de debate, la controversia (el debate — tal y como lo entiende DASCAL (DASCAL, 2007) — basado en argumentos, y que ocupa una posición intermedia entre una discusión científica y una mera disputa entre conflictos de preferencias que son irresolubles) que debería jugar un papel de gran importancia como medio de expresión iusfilosófico.

\section{1.}

La expresión «globalización de un localismo» es de BOAVENTURA SANTOS, y sirve muy bien para expresar sintéticamente mucho de lo que ocurre en el mundo global con la cultura, incluida la cultura iusfilosófica. Conviene entonces adoptar cierta actitud de cautela o de sospecha en relación con las modas iusfilosóficas que se nos imponen (básicamente desde el mundo anglosajón) y, en todo caso, en relación con la manera de tratar esos tópicos de moda. Por ejemplo, ¿es la distinción entre positivismo jurídico incluyente, excluyente y normativo la más relevante que puede trazarse para discutir acerca del positivismo jurídico? ¿No merecería la pena tener en cuenta también la dimensión histórica de esa dirección del pensamiento jurídico? ¿Y se puede presentar el 
debate en torno al positivismo jurídico de la misma manera en los países anglosajones y en los del mundo latino: tiene las mismas connotaciones ser un iusnaturalista (si es que esa fuera la única alternativa al positivismo jurídico) en Buenos Aires o en Madrid que en Harvard o en Oxford? ¿Y por qué olvidar, en todo caso, contribuciones a esa polémica tan importantes como la de CARRIÓ [quizá el primer «positivista incluyente»: nada menos que en 1970 (en CARRIÓ, 1986)], la de SCARPELLI [que defendió a mitad de los años sesenta y con una extraordinaria penetración lo que ahora suele llamarse positivismo normativo o valorativo (SCARPELLI, 1965)] o la de GONZÁLEZ VICÉn [en varios trabajos de los años cincuenta y sesenta del siglo XX que, en mi opinión, representan la mejor caracterización —en clave histórica — que tenemos del positivismo jurídico (GONZÁLEZ VICÉN, 1979)]?

\section{2.}

Que la filosofía del derecho representa una aproximación general al fenómeno jurídico es algo que no ofrece ninguna duda. Pero lo que no es ya tan obvio es cómo de general ha de ser esa aproximación. Por supuesto, existen enfoques —enfoques valiosos- que son, por así decirlo, completamente generales y que sería absurdo abandonar: por ejemplo, el del análisis lógico de los conceptos básicos del derecho. Pero la filosofía del derecho no se acaba ahí, no tiene por qué acabarse ahí. Recuérdese la famosa polémica entre HART y DWORKIN, una de cuyas claves es el propósito del primero de construir una teoría descriptiva del derecho y que pretende servir para cualquier sistema jurídico (mínimamente desarrollado), mientras que el objetivo del segundo era el de construir una teoría normativa circunscrita al derecho de los Estados Unidos (y, por extensión, al de los derechos de los Estados constitucionales). ¿Pero supone lo anterior un criterio para optar, digamos, por HART frente a DWORKIN? Y, por cierto, ese carácter menos general del enfoque de DWORKIN, cle hace ser por ello menos «universal»? ¿No tendría entonces sentido proponerse elaborar, de manera central, una teoría del derecho de los Estados constitucionales del mundo latino que, desde luego, no podría prescindir de los otros enfoques a que me he referido, pero que pusiera el acento en las peculiaridades de nuestros sistemas jurídicos?

\section{3.}

Al fin y al cabo, la filosofía del derecho viene a ser (al menos, desde cierto punto de vista) una filosofía regional o particular en relación con la filosofía general, pero eso, claro está, no tiene por qué llevar a dejar de considerarla como una filosofía. En mi opinión, la mejor filosofía del derecho es probablemente la que mantiene una adecuada (y estrecha) conexión con la filosofía general, lo que significa que recibe de esta última ciertos materiales (ideas) que, debidamente transformados en el mundo jurídico, pueden revertir luego al campo de origen. Me parece que una ilustración de esa manera de proceder la encontramos en la teoría del discurso de ALEXY. Como se sabe, él toma la noción de HABERMAS (de la filosofía general), pero no se limita a aplicarla sin más al campo jurídico, sino que la enriquece y la transforma con lo que, al final, lo que regresa 
al campo de la filosofía general es una idea más articulada y que seguramente los filósofos generales harían muy bien en tomar en cuenta. ¿Y no cabría pensar en que algo parecido podría tener lugar entre la filosofía del derecho tout court y, por ejemplo, la filosofía del derecho del mundo latino si bien, en uno y otro caso, el «movimiento» de las ideas no tendría por qué provenir siempre del primero de los campos: de la filosofía general o de la filosofía del derecho tout court?

\section{4.}

No es fácil, en todo caso, precisar en qué debería ser distinta esa filosofía del derecho del mundo latino en relación con otras filosofías del derecho «regionales». Pero me parece que esos posibles rasgos diferenciales tendrían que buscarse en relación con la materia o los problemas preferentes de estudio, con el método a emplear y con la función o finalidad perseguida. Me limitaré a hacer, al respecto, algunas preguntas que, yo creo, tiene sentido plantearse y tratar de contestar, quizás como una tarea previa a la de fijar del todo esas características. ¿Estamos los filósofos del derecho del mundo latino volcados (u orientados preferentemente) a las cuestiones que tenemos razones para considerar como las más relevantes en nuestras culturas jurídicas? ¿Nos hemos preocupado por desarrollar las herramientas metodológicas que podrían servirnos a nosotros (y a los otros operadores jurídicos) para resolver o esclarecer los problemas relevantes que plantean el funcionamiento de nuestros sistemas jurídicos? ¿Hemos reflexionado suficientemente sobre cuál tendría que ser el papel de la filosofía del derecho en el conjunto del saber jurídico (tal y como es practicado en nuestros medios) y de los saberes sociales y de la filosofía (tal y como se dan también en nuestros medios)? $¿ Y$ acaso las respuestas a todas esas preguntas no nos llevarían a procurar elaborar una filosofía del derecho menos «seguidista» que la que solemos practicar?

\section{1.}

Estar inserto en una tradición de pensamiento es probablemente uno de los requisitos necesarios para poder hacer de manera significativa filosofía del derecho. Pero para que exista una tradición no basta con que hayan existido pensadores de talla suficiente y con que ellos hayan producido obras importantes. Se necesita también que se hayan creado instituciones, esto es, organizaciones con fines compartidos por quienes la integran y que aseguren cierta continuidad, cierta pervivencia, a lo largo del tiempo. En el mundo latino no faltan esos autores relevantes. Sin salir del siglo XX, se podrían dar unos cuantos nombres que permitirían, a partir de ellos o de sus obras, fundar una tradición. Me limito a señalar tres: Norberto BOBBIO, Carlos VAZ FERREIRA y Carlos NinO. Hemos carecido sin embargo, y me parece que en buena medida seguimos careciendo, de instituciones capaces de hacer fructificar esas obras, de darles continuidad. ¡Qué diferencia con lo que ha ocurrido en el ámbito anglosajón! La influencia de AUSTIN llega hasta mediados del siglo XX y es con él, con su concepción imperativista del derecho, con quien discute fundamentalmente HART. Al igual que es al positivismo hartiano al que DWORKIN toma como modelo que pretende superar. Los integrantes 
del movimiento Critical Legal Studies se afanan por mostrar los límites del liberalismo dworkiniano. Etcétera.

\section{2.}

La presencia del Estado constitucional como forma de organización política aceptada casi sin excepciones en el mundo latino parecería ofrecer una base sólida sobre la que edificar una filosofía del derecho para estos países. Pero para ello hay dos obstáculos que habría que superar y que, en buena medida, están en el centro de la discusión en los últimos tiempos. Uno es el formalismo en cuanto concepción, ideología, profundamente arraigada en nuestra cultura y que, simplificando, viene a consistir en reducir el derecho a reglas y en aislar el derecho de otros fenómenos sociales y culturales. El otro, el defecto opuesto, consiste en ignorar que el derecho es - aunque no sea sólo eso- un fenómeno autoritativo en el que las reglas tienen que jugar un papel preponderante; en reducir, por así decirlo, el derecho a principios, a valores; y en hacer, por tanto, que el derecho pierda uno de sus rasgos de identidad y pase a ser considerado como un capítulo más de la moral. Quizá no exista un término aceptado por todos para designar esta segunda concepción, pero yo creo que podría servir el de «neo-constitucionalismo», en el sentido que le atribuyeron quienes acuñaron el término y, en general, quienes se califican a sí mismos de «neo-constitucionalistas». Pues bien, se trata, así entendida, de una concepción del derecho que no es compatible con el constitucionalismo post-positivista de autores como DwORKIN, como ALEXY o como NinO. La filosofía del derecho del mundo latino, en mi opinión, debería ser constitucionalista, pero no neo-constitucionalista.

\section{1.}

Hay una curiosa ficción que, a lo largo de los últimos años, he podido ver que aceptan muchísimos iusfilósofos del mundo latino y en la que se basan también las agencias de evaluación de la investigación que operan, con creciente influencia, en el contexto de nuestras universidades. La ficción consiste en suponer que la filosofía del derecho supone un tipo de actividad semejante a la de la matemática, la física y la biología, en el sentido de que, tanto en un campo como en los otros, existen instituciones de ámbito mundial que integran a la comunidad de sus cultivadores (la IVR para los iusfilósofos), organizan congresos de ámbito mundial en los que se discuten los avances en la materia siguiendo las reglas del diálogo racional, etc. Las cosas, sin embargo, no son exactamente así: entre cómo están organizadas esas disciplinas científicas y cómo lo está la filosofía del derecho existen diferencias muy considerables. Cito un texto de un artículo reciente (ATIENZA, 2012):

No existe ninguna estructura institucional en la que los trabajos iusfilosóficos puedan competir entre sí en un plano de igualdad, en la que cualquier idea pueda llegar a imponerse a sus rivales si es que cuenta con mejores argumentos en su favor. Y no existe porque ese tipo de diálogo — de diálogo racional- presupone ciertos requisitos que están manifiestamente ausentes en el ámbito de la filosofía del derecho. Está ausente, sin ir 
más lejos, el interés en escuchar por parte de quienes — se supone- tendrían que ser los destinatarios de esos mensajes. Y no hay, por otro lado, por qué considerar que se trata de un desinterés culpable: no hay nada que reprochar a quien no te escucha porque simplemente no conoce tu lengua o porque vive y trabaja inserto en un tejido institucional -en una cultura jurídica - que cuenta con sus reglas propias de funcionamiento, las cuales le llevan a comportarse de manera «autopoiética». Simplemente, el derecho no es como las matemáticas, como la biología o como la física. Hoy por hoy, la «ciencia del derecho» (en el sentido amplio e impreciso de la expresión) sigue siendo, en muy buena medida, una ciencia de cada pueblo o de cada cultura. Por lo demás, esa relación de asimetría comunicativa que caracteriza a la filosofía del derecho tiene, naturalmente, algunas excepciones y, en todo caso, no es una razón para dejar de escuchar a quien, aunque no esté en disposición a su vez de escucharnos, sin embargo, tiene algo interesante que decirnos. Pero lo que no parece tener mucho sentido - para expresarlo de manera cruda- es empeñarse en escribir textos iusfilosóficos que parecerían tener como objetivo último el de aparecer citados —naturalmente, solo en nota a pie de página - en alguna obra de un autor anglosajón. Podemos aspirar a más» (p. 128).

\section{2.}

Si se deja de creer en ficciones como la que acabo de señalar, es probablemente más fácil que se acepte la necesidad, o la conveniencia, de una «implantación política» de la filosofía del derecho que asuma como una de sus funciones la de mediar entre lo local y lo global; lo que no podrá hacerse si no se construye, a su vez, una teoría de ámbito regional dirigida a dar cuenta y a guiar las prácticas jurídicas en el contexto de nuestros Estados constitucionales.

Entiéndaseme bien, no se trata de ir contra organismos como la IVR que, en términos generales, juegan un papel positivo, ni de defender una especie de «nacionalismo iusfilosófico» que seguramente traería males semejantes a los producidos por el nacionalismo en el campo de la política: el populismo, la confusión ideológica, etc. Se trata de no engañarse y de construir una filosofía del derecho apoyada sobre el suelo firme que supone la realidad de nuestros derechos y de nuestras culturas jurídicas.

\section{1.}

Vuelvo sobre un punto anterior. Nos empeñamos muchas veces en escribir textos iusfilosóficos dirigidos a un destinatario que no existe, porque no está en condiciones de escuchar o porque no está dentro de sus intereses el hacerlo. Y nos olvidamos, al mismo tiempo, de que contamos con un auditorio potencial de enormes dimensiones y que reposa sobre un suelo fértil en el que podrían crecer y fructificar las ideas iusfilosóficas. También aquí (estoy hablando de un pragmatismo bien entendido) haríamos bien en seguir el modelo de la iusfilosofía anglosajona que en muchos aspectos ha sabido institucionalizar con éxito la teoría del derecho. Además, nosotros estamos, en relación con ellos, en una situación de cierta superioridad que deberíamos ser capaces de aprovechar. Pues mientras que ellos viven inmersos prácticamente en una sola cultura, nosotros tenemos acceso por lo general a varias de ellas: a la nuestra (a las nuestras) y, con ciertas limitaciones, también a la suya. Pero para que esto se convierta realmente 
en una ventaja es necesario que en lugar de navegar sin rumbo, perdidos de un lado para otro, sepamos con alguna precisión cuál es nuestro puerto de destino y cuáles las mercancías que tendríamos que desembarcar.

\section{2.}

La metáfora anterior la utilizaba IHERING para dar cuenta de cuál era en su opinión la función (práctica) del jurista (semejante a la del marino que tiene que llevar a puerto determinadas mercancías) que, por supuesto, sirve también para el filósofo del derecho. Las fronteras entre el trabajo del jurista práctico, del que elabora la dogmática jurídica y del filósofo del derecho son (o deberían ser) fluidas. Hace algunos años, DWORKIN (2007) escribió un texto (proveniente de una conferencia) defendiendo que los juristas (en particular los jueces — sobre todo, los jueces constitucionales-) debían y podían ser filósofos. Tenía razón, pero quizás merezca la pena hacer notar que al hablar de los filósofos cuyas obras recomendaba leer a los juristas de su país, aparte de a los filósofos clásicos, sólo incluía, entre los contemporáneos, a autores estadounidenses. Como se ve una vez más, una prueba de que una concepción no ya «regionalista», sino bien «localista» de la filosofía del derecho puede llegar a tener un alcance muy universal.

\section{3.}

La falta de pragmatismo es, en mi opinión, el defecto fundamental de la filosofía del derecho que se suele elaborar en el mundo latino. Pero a lo que me refiero, como antes decía, es a un pragmatismo bien entendido que nada tiene que ver con el pragmatismo ramplón del jurista que vive a ras de suelo y que no es capaz de entender que en el derecho se necesitan teorías precisamente para poder ser suficientemente prácticos. Ni tampoco con el «nuevo pragmatismo» de RORTY y compañía, cuyo escepticismo radical en relación con la razón — práctica y teórica- no puede significar otra cosa que la negación de la filosofía del derecho; por lo menos, de la que aquí se pretende bosquejar.

El pragmatismo al que estoy apelando podría entenderse, básicamente, como una actitud o un presupuesto último del pensamiento iusfilosófico, consistente en dar primacía a la práctica. Es, pues, obvio que bajo ese rubro caben no una sola, sino una pluralidad de concepciones iusfilosóficas.

\section{1.}

¿No cabría pensar en que existe alguna conexión entre la incapacidad de los filósofos del derecho del mundo latino para incidir significativamente en la cultura jurídica de nuestros países y el excesivo seguidismo del paradigma anglosajón (no de su orientación pragmatista general — que me parece completamente adecuada-, sino en relación con la agenda de problemas, la forma de tratarlos y las finalidades concretas que 
ese paradigma establece)? ¿Puede extrañarnos que los juristas no filósofos del derecho hayan decidido prescindir de nosotros cuando nosotros no parecemos aspirar a otra cosa que a comentar ideas surgidas en otros contextos y a ser actores muy secundarios de representaciones que tienen lugar, en realidad, en escenarios muy lejanos? ¿Qué tal si nos tomáramos en serio el lema que, según KANT, sintetizaba el espíritu de la Ilustración: ¡atrévete a pensar!? ¿O tal vez no hemos llegado aun, en este considerable fragmento de humanidad que representa el mundo latino, a la mayoría de edad?

\section{2 .}

Quizá no sea fácil determinar cuáles son los problemas iusfilosóficos relevantes. La noción de relevancia es, naturalmente, relativa a la concepción del derecho y de la filosofía del derecho que se tenga. Es más, un criterio que habría que considerar a la hora de optar por una u otra concepción de la filosofía del derecho podría ser el de tener en cuenta cuáles son los problemas relevantes que cada una de esas concepciones lleva a tratar.

Pero si se está de acuerdo en que la noción de problemas relevantes supone algo así como «relevantes para la comunidad jurídica entendida en un sentido amplio», eso tendría que llevarnos probablemente a cerrar las puertas a mucho de lo que BOBBIO llamó en una ocasión «filosofía del derecho de los filósofos», precisamente porque si no se cuenta con cierto grado de familiaridad con el derecho, es imposible dar satisfacción a esa exigencia de relevancia. Pero el cumplimiento de la condición de relevancia, desde luego, es compatible con — por no decir que exige habitualmente- grados muy elevados de abstracción. Y conviene no olvidar que muy abstracto no quiere decir muy abstruso. Y que si lo que se pretende es escribir para un público amplio, que vaya más allá del configurado por los propios iusfilósofos (cuando no por los iusfilósofos que han escrito sobre tal tema o que siguen tal orientación), entonces hay ciertos consejos fáciles de dar pero seguramente más difíciles de seguir y que ni siquiera merece la pena explicitar aquí por su obviedad.

\section{1.}

Desde luego, supone una considerable simplificación reducir a esas tres concepciones (el positivismo jurídico, el iusnaturalismo y la teoría crítica) el panorama actual de la filosofía del derecho. Pero a veces las simplificaciones pueden estar justificadas y, en todo caso, no cabe duda de que esas tres orientaciones (entendidas en un sentido suficientemente amplio) muestran tener un arraigo y una permanencia en el tiempo que no pueden deberse a una mera moda intelectual; quiero decir que tienen que estar apuntando, cada una de ellas, a algún ingrediente importante de la experiencia jurídica. Lo cual no debe llevar tampoco a proponer lo que sería una (pseudo)síntesis conciliadora que, en mi opinión, significaría todo un acto de traición a la filosofía. Cito de nuevo un pasaje del mismo trabajo al que antes me refería (ATIENZA, 2012):

Entiéndaseme bien. No estoy abogando en favor de un sincretismo iusfilosófico que tome un poco de aquí y otro poco de allá, dirigido a armar una especie de componenda 
intelectual en la que cada cual pueda reconocer algo de lo suyo, de manera que al final pueda llegarse a algo así como a un acuerdo negociado. No es así, obviamente, como hay que construir una teoría que merezca la pena e incluso el nombre de tal. De hecho, mi opinión sobre el positivismo jurídico (en todas sus formas) es que se trata de una concepción del derecho históricamente periclitada a la que, simplemente — para utilizar el título de un trabajo escrito conjuntamente con Juan RUIZ MANERO-, debemos dejar atrás; al igual que la filosofía del derecho - pero hace ya cosa de un par de siglos- debió dejar atrás las doctrinas del derecho natural; y, en relación con las llamadas teorías «críticas» del derecho, mi objeción fundamental a las mismas es que, simplemente, no están en condiciones de dar cuenta del derecho del Estado constitucional y, en consecuencia, no pueden tampoco guiar las prácticas jurídicas que se desarrollan en ese contexto. Pero, al mismo tiempo, aunque uno no pueda ser ya ni positivista, ni iusnaturalista, ni «crítico», no veo ninguna razón para dejar de apropiarse de lo que pudiera haber (de lo que hay) de valioso en esas (o en otras) tradiciones, para no tener hacia ellas — si se me permite hablar así — una actitud no sólo pragmática, sino incluso «oportunista» (pp. 126-127).

\section{1.}

La herencia dejada por el positivismo a nuestra cultura jurídica es un tanto ambigua y necesita de alguna clarificación. Quizá la precisión más importante a hacer consista en distinguir entre el positivismo de los juristas (de los cultivadores de la dogmática jurídica y de los juristas prácticos) y el de los teóricos del derecho. El de los primeros ha sido, fundamentalmente, un positivismo formalista que sigue lastrando gravemente nuestra cultura, pero que raramente ha sido defendido por los filósofos del derecho del mundo latino. Es más, el positivismo metodológico que ha prevalecido entre nosotros (siguiendo las huellas de KELSEN o de HART) es simplemente incompatible con el formalismo jurídico, entendida esta última expresión en su sentido usual (y peyorativo).

\section{2.}

A los positivistas jurídicos (empezando por BOBBIO) les debemos una preocupación por la clarificación conceptual y la construcción de un método de análisis del lenguaje de los que sería insensato prescindir: de la actitud y del método. No se trata, pues, de olvidarse de las aportaciones iuspositivistas a la teoría del derecho, sino de considerarlas, en general, más como un punto de partida a la hora de estudiar un determinado problema (por ejemplo, el de la interpretación), que como un punto de llegada.

\section{3.}

La necesidad de superar el positivismo jurídico, el tipo de positivismo que ha prevalecido en la teoría del derecho del mundo latino y que sigue aun teniendo una considerable fuerza, se debe a estos dos factores a los que ya anteriormente me he referido. Por un lado, al reducir el derecho a un fenómeno de autoridad, el positivismo configura una concepción excesivamente pobre del derecho y que para nada da cuenta de la 
experiencia jurídica que caracteriza el derecho del Estado constitucional. Y, por otro lado, al sostener la tesis del escepticismo moral se renuncia a poder edificar una teoría verdaderamente práctica del derecho: no es casual que el positivismo jurídico haya sido considerado por los propios positivistas [como PRIETO (2000) o ATRIA (1999)], como una teoría del derecho que carece de una teoría de la argumentación jurídica, o que (como en el caso de FERRAJOLI) se construya una teoría ambiciosa del derecho dirigida a la protección y salvaguarda de los derechos fundamentales..., que sin embargo, no puede fundamentar.

\section{1 .}

La superación del positivismo jurídico no supone (no debe suponer) una vuelta al derecho natural. Al igual que hoy, en la época del constitucionalismo, no tiene ya sentido ser un partidario del positivismo jurídico, el iusnaturalismo dejó de ser una concepción del derecho acorde con los tiempos desde hace algo más de dos siglos. Para decirlo con GONZÁLEZ VICÉN, desde que, con el fenómeno de la «positivización» que tuvo lugar en Europa desde finales del XVIII, el derecho dejó de ser considerado como un orden de la conducta con validez para todos los tiempos y lugares y pasó a ser contemplado como algo histórico, como una creación humana relativa a sociedades concretas (lo que solemos llamar tesis de las fuentes sociales del derecho), y que requería un tipo de elaboración teórica que no podía ser ya la de las doctrinas iusnaturalistas. Es más (tanto GONZÁLEZ VICÉN como BOBBIo lo señalaron en alguna ocasión), el propio término «filosofía del derecho» empieza a ser usado a comienzos del XIX para tratar, aproximadamente, de las mismas cuestiones que hasta entonces se contenían en los tratados de «derecho natural».

Pues bien, lo que el constitucionalismo contemporáneo critica a los partidarios del positivismo jurídico no es que estos últimos consideren el derecho como un fenómeno artificial, como una creación humana, sino: 1) su pretensión de que el derecho puede identificarse, interpretarse, etc. prescindiendo de la moral, o sea, el aislamiento del derecho en relación con la razón práctica; 2) el escepticismo axiológico (bien se emplee esa expresión o bien la de no-cognoscitivismo o relativismo moral), o sea, la negación de que los juicios de naturaleza ética sean susceptibles de justificación racional. Considerar como iusnaturalista a toda concepción del derecho que niegue las dos anteriores tesis no es más que una maniobra retórica en la que los autores positivistas vienen a coincidir precisamente con algunos iusnaturalistas (como FINNIS), aunque cada uno de ellos lo haga con propósitos muy distintos: los primeros, para denostar una concepción del derecho, dadas las connotaciones muy negativas (intolerancia política, arcaísmo conceptual, etc.) que el rótulo de «iusnaturalismo» tiene (y par cause) en muchos ámbitos de la cultura jurídica de los países latinos; los segundos, para seguir sosteniendo una versión aristotélico-tomista del derecho natural que, sorprendentemente, tendría que ser el fundamento de la reflexión jurídica en las sociedades globalizadas del presente, pero que acaba por servir de vehículo (lo que ya no tendría por qué suponer una sorpresa) para la defensa de tesis extremadamente conservadoras a propósito de temas tales como el aborto, la eutanasia, el matrimonio entre personas del mismo sexo o el trato a los inmigrantes (FINNIS, 2012: 76). El constitucionalismo jurídico (el tipo 
de concepción en la que se puede incluir a autores como DwORKIn, AlEXy, NinO, MACCORMICK ) es realmente una posición distinta a la del positivismo jurídico y a la del derecho natural. Y es precisamente esa vía la que debería transitar sobre todo la filosofía del derecho del mundo latino.

\section{2 .}

El derecho no puede entenderse sino en el contexto de la razón práctica, cuyo carácter unitario (una unidad presidida por la moral) constituyó, quizás, el principal empeño teórico de Carlos NiNO. Como él no se cansó de defender, el derecho no es un fenómeno insular, y la filosofía del derecho tiene que entenderse en términos de interconexión con la filosofía moral y la filosofía política. Ahora bien, la existencia de muchos puentes entre el derecho, la moral y la política no implica (y NiNO, desde luego, era bien consciente de ello) reducir el derecho a los otros fenómenos. En particular, no supone negar al razonamiento jurídico justificativo cualquier tipo de autonomía en relación con el razonamiento moral. Esta última sería (como se indicó en 3.2) una tesis típica del neoconstitucionalismo, pero no del constitucionalismo jurídico. O sea, el razonamiento jurídico contiene siempre un fragmento de razonamiento moral, pero esas razones morales (por paradójico que pueda parecer) pueden en ocasiones justificar que se acuda a razones autoritativas (razones jurídicas) que no serían las mejores desde un punto de vista estrictamente moral el derecho y la moral, en definitiva, están lejos de ser fenómenos coextensivos.

\section{3.}

El objetivismo moral, cuando se entiende de manera adecuada, puede resultar una tesis bastante más fácil de aceptar de lo que muchos creen. Y, desde luego, es un presupuesto necesario para hacer filosofía del derecho con sentido. 1) De entrada, conviene recordar que el positivismo jurídico no se ha caracterizado comúnmente por ser contrario al objetivismo ético, sino por sostener la tesis de la separación entre el derecho y la moral. Como se sabe, los positivistas de la Jurisprudencia analítica inglesa (BENTHAm y Austin) fueron objetivistas éticos. A diferencia de KELSEN o de Ross que defendieron (sin duda, influidos por el positivismo lógico de la época) tesis fuertemente no-cognoscitivistas en materia moral. Pues bien, lamentablemente, es ese nocognoscitivismo (bastante ajeno al gran desarrollo que ha conocido la filosofía moral en las últimas décadas) lo que parece estar en la base de lo que hoy, en el mundo latino, sostienen autores positivistas tan influyentes como FERRAJOLI, GUASTINI, COMANDUCCI o Bulygin. 2) Además, los no-cognoscitivistas parecen empeñados en negar el objetivismo ético basándose en (atrincherados tras) una concepción de la verdad que sólo sería aplicable a los enunciados de la ciencia natural y de la ciencia formal. Pero el objetivismo ético no está comprometido con la tesis de que existen «verdades éticas» en el mismo sentido en que se habla de verdades en el ámbito de la ciencia. Como recientemente ha escrito DWORKIN (2011: 42-43), es cierto que en el mundo de la moral no existen «morons» que sean los equivalentes a los «átomos» del mundo físico. Pero ser 
objetivista en materia moral significa simplemente considerar que los juicios morales pueden estar o no justificados en términos racionales; no que sean verdaderos o falsos, sino correctos o incorrectos. 3) La clave radica entonces en preguntarse cuáles son esos criterios de corrección, y la respuesta (la respuesta en la que, con diferencias de énfasis, vienen a coincidir las diversas concepciones de la ética a las que suele denominarse constructivistas) es que son los que determina el procedimiento de la discusión racional, cuyas reglas rigen tanto en relación con cuestiones teóricas como prácticas. Y dado que una de esas reglas es la del carácter abierto del diálogo racional, lo que de ahí se sigue es que el procedimiento permite arribar a juicios de validez objetiva, pero no absoluta: nuevos argumentos no considerados hasta el momento podrían hacer que tuviésemos que corregir un juicio considerado hasta entonces como correcto. O sea, el objetivismo moral no es absolutismo moral: los juicios morales incorporan una pretensión de corrección, no de verdad absoluta.

\section{1 .}

Uno de los mayores déficits de la teoría jurídica del mundo latino (y de la teoría jurídica tout court) es que se ha construido sin considerar apenas el conocimiento social disponible. Y esa carencia tiene seguramente mucho que ver con una inadecuada relación con la tradición de pensamiento que se inicia con Karl MARX. En general, puede decirse que los teóricos del derecho han dejado en las últimas décadas de leer a MARX. No digo que hayan dejado de ser marxistas, lo que resultaría enteramente comprensible, sino que han dejado de considerar su obra como la de un autor clásico que todavía tiene muchas cosas que decirnos. Pues de la misma manera que es recomendable leer la Ética a Nicómaco o la Retórica de ARISTÓTELES sin que, naturalmente, ello presuponga la aceptación de la esclavitud o de la teoría de los silogismos en bloque, uno puede leer a MARX — y obtener de ello un provecho considerable — sin necesidad de pensar que el comunismo es un estadio necesario en el desarrollo de la historia, que el derecho y el Estado están destinados a extinguirse, etc. En particular, hay una serie de ideas que se encuentran en el pensamiento de MARX y que son de gran valor para la construcción de una teoría del derecho para el mundo latino en el sentido que aquí se está defendiendo. Así: el pragmatismo (la primacía de la praxis); el enfoque funcional, crítico y materialista de los fenómenos sociales; la propuesta de considerar el derecho a partir de una concepción global de la sociedad, lo que lleva a abrir los saberes jurídicos hacia las ciencias sociales; o el compromiso con un proyecto político-ético de emancipación humana en el que el derecho no tendría por qué verse relegado.

\section{2.}

Sin embargo, los iusfilósofos que vienen de esa tradición siguen, por lo general, manteniendo dos tesis que dificultan o hacen imposible que el derecho de los Estados constitucionales pueda jugar ese papel emancipatorio. Reconocer esta función, por cierto, no implica una idealización de los sistemas jurídicos (incluidos los del Estado constitucional). El derecho contemporáneo (el de los Estados constitucionales) es, des- 
de el punto de vista político-moral, un fenómeno esencialmente ambiguo, necesariamente vinculado con todos los procesos tanto de dominación como de emancipación social. De ahí lo inadecuado de sostener la tradicional tesis marxista consistente en ver el derecho como un elemento meramente superestructural y al que se atribuye una relevancia más bien escasa en el conjunto de la sociedad. Tesis, por lo demás, que resulta agravada al haber calado ampliamente entre los científicos sociales y los filósofos, los cuales (al menos en el ámbito de nuestra cultura) creen poder explicar los fenómenos sociales (o incidir significativamente en los mismos) ignorándolo prácticamente todo sobre uno de sus componentes esenciales.

La otra tesis es la del escepticismo en materia de ética, la imposibilidad de construir un discurso objetivo sobre lo correcto y lo incorrecto. En esto, los autores de inspiración marxista (los «críticos») vienen a coincidir ampliamente con los positivistas, pero mientras que para estos últimos el no-cognoscitivismo en materia de moral no tendría por qué afectar en principio a su concepción del derecho (que suele tener, por lo general, pretensiones tan solo de tipo cognoscitivo o descriptivo), en el caso de los autores «críticos» (o de los positivistas que defienden una implantación política de la iusfilosofía — como es el caso de FERRAJOLI-) las consecuencias son más bien letales pues, simplemente, no parece que una pretensión de guiar la práctica, de hacer avanzar un programa de emancipación social, sea compatible con la falta de criterios moralmente justificados para criticar un tipo de práctica y proponer otra en su lugar.

A veces, autores de inspiración marxista (estoy pensando también aquí en CAPELLA o en FERRAJOLI) parecen pensar que la dificultad que se acaba de señalar puede superarse apelando a algún tipo de convención que el desarrollo histórico de las sociedades habría hecho surgir. Pero la debilidad de esa concepción de la justicia (quizás heredera del historicismo y el no-cognoscitivismo del propio MARX en esta materia) me parece manifiesta. Si el único fundamento al que podemos apelar es la convención misma, ¿cómo se puede defender que un programa que pretende instaurar una sociedad - pongamos por caso- erigida sobre los principios de igualdad y solidaridad es superior a la hoy dominante que viene a ser la materialización de los principios del neoliberalismo? ¿Acaso la concepción neoliberal no se basa también en una convención ampliamente aceptada en muchos sectores de nuestras sociedades?

\section{3.}

Los autores «críticos» (en un sentido amplio que incluye tanto a los de inspiración marxista como a realistas radicales - como HABA-) han estado ocupados con excesiva frecuencia más en ser críticos que en desarrollar una teoría del derecho que pudiera servir realmente para transformar el derecho y la sociedad. Han incurrido así en lo que en alguna ocasión he denominado «el dilema del crítico». Se trata de lo siguiente (ATIENZA, 1996). Los juristas críticos (y, muy en particular, los del movimiento Critical Legal Studies) se caracterizan por sostener tres tesis que se dirigen, respectivamente, contra el esencialismo, el formalismo y el liberalismo; esas tres tesis son las del carácter contradictorio, indeterminado e ideológico del derecho. Pues bien, si las mismas se entienden en un sentido fuerte o radical, el problema que se plantea es que el crítico se 
niega a sí mismo, pues si el derecho fuera absolutamente contradictorio, indeterminado e ideológico, entonces sería imposible —o inútil— cualquier tipo de teoría jurídica, incluida la suya; dicho de otra manera, la versión fuerte es insostenible. Pero si las tesis se entendieran en un sentido débil, entonces el crítico entra en crisis de identidad pues, obviamente, no hace falta ser un «crítico» para sostener eso.

Pues bien, la manera de salir del dilema radica, por un lado, en despreocuparse un tanto de esos afanes de radicalidad y poner en su lugar una mayor dosis de pragmatismo político y de sentido de la responsabilidad (en relación con el primer cuerno del dilema); y, por otro lado (para escapar del segundo cuerno), en aceptar fragmentos más o menos extensos de teorías que bien podrían haberse elaborado dentro del paradigma liberal y/o analítico. Un buen ejemplo de lo que quiero decir lo suministra la temática de los derechos humanos; en particular, de los derechos sociales. Lo que ahora tenemos son teorías demasiado escoradas hacia el lado del liberalismo político (aunque se trate de un liberalismo progresista, como el de DwOrKIN o NINO) y que, en consecuencia, no consiguen dar cuenta adecuadamente de los derechos sociales. Pero para lograr esto último no es preciso prescindir, por ejemplo, de los tres principios elaborados por NiNO para la justificación de los derechos humanos (autonomía, inviolabilidad y dignidad). Bastaría con reinterpretarlos o, quizás mejor, con añadir otros tres principios procedentes de la tradición socialista (el principio de las necesidades básicas, de cooperación y de solidaridad) para dar paso así a una teoría sobre el concepto y la fundamentación de los derechos humanos más acorde con la noción de Estado constitucional con la que, seguramente, muchos iusfilósofos del mundo latino están comprometidos.

\section{3.}

Por qué todo lo anterior se conecta con una visión argumentativa del derecho no es, en mi opinión, difícil de explicar. El derecho no es, por supuesto, únicamente argumentación, pero la dimensión argumentativa del derecho es particularmente relevante en el contexto del Estado constitucional. Ese enfoque permite conectar de una manera que me atrevo a calificar de «natural» la teoría con la práctica: permite volver operativas para los juristas muchas de las construcciones doctrinales elaboradas en el marco de la teoría del derecho (la teoría de las fuentes, de los enunciados jurídicos, de la validez, de la interpretación ). Conecta a la filosofía del derecho con la filosofía general (teoría general de la argumentación, filosofía moral y política) y con los saberes sociales (psicología cognitiva, teoría de la decisión, sociología jurídica). Y lleva, en definitiva, a tener que servirse del método analítico para, sobre la base de cierto objetivismo moral (sin el cual no cabría hablar propiamente de criterios de corrección ni de argumentación jurídica justificativa), facilitar la toma de decisiones encaminadas a mejorar el derecho y la sociedad. Además, hablando en términos generales, en el mundo latino carecemos de una sólida cultura argumentativa, de manera que contribuir a desarrollar ese enfoque entre los juristas puede tener un cierto efecto de irradiación hacia otras instituciones sociales, lo que sería, sin duda, de un gran valor: la capacidad argumentativa de los ciudadanos es una condición necesaria para poder calificar a una sociedad de democrática. 


\section{BIBLIOGRAFÍA}

Atienza, M., 1996: Prólogo a Juan Antonio PÉREz Lledó, «El Movimiento», Critical Legal Studies, Madrid: Tecnos.

- 2008: «¿Es el positivismo jurídico una teoría aceptable del Derecho?», en Ideas para una filosofía del Derecho. Una propuesta para el mundo latino, Lima: Universidad Inca Garcilaso; el trabajo reproduce su intervención en el debate sobre «El futuro del positivismo jurídico», que tuvo lugar en el XXIII Congreso de la IVR, en Cracovia, en agosto de 2007.

— 2009a: «¿Por qué leer a Marx hoy», en el volumen colectivo del mismo nombre, con participación de L. SAlAZAR CARRIÓN y A. CóRdOva, México: Fontamara.

- 2009b: «Una nueva visita a la filosofía del Derecho en Argentina», en Academia. Revista sobre enseñanza del Derecho, año 7, núm. 14, 9-30.

- 2012: «Una teoría pragmática del diritto», en Rivista di filosofia del diritto. Journal of Legal Philosophy, 1/2012, 123-134.

ATRIA, F., 1999: «Del derecho y el razonamiento jurídico», en Doxa, núm. 22.

BobBio, N., 1950: Teoria della scienza giuridica, Torino: Giappichelli.

- 1980: Contribución a la teoría del Derecho, A. Ruiz Miguel (ed.), Valencia: Fernando Torres, 1980.

Bulygin, E., 1992: «Sull’ interpretazione giuridica», en Analisi e diritto, 1992.

CARRIÓ, G., 1986: «Principios jurídicos y positivismo jurídico», ahora en Notas sobre derecho y lenguaje, 3. ${ }^{a}$ ed. aumentada, Buenos Aires: Abeledo-Perrot.

DASCAL, M., 2007: «Tipos de polémicas y tipos de movimientos polémicos», en R. MARAFIOTI (ed.), Parlamentos: Teoría de la argumentación y debate parlamentario, Buenos Aires: Biblos.

DwORKIN, R., 2007: «¿Deben nuestros jueces ser filósofos?», en Estudios de Derecho, núm. 144, Medellín, diciembre.

- 2011: Justice for Hedgehogs, Harvard University Press, 2011.

FerRajoli, L., 2010: Principia iuris. Teoría del derecho y de la democracia, Madrid: Trotta.

- 2011: «Constitucionalismo principialista y constitucionalismo garantista», en Doxa, núm. 34; publicado también, en L. FERRAJOLI y otros, Un debate sobre el constitucionalismo, Madrid: Marcial Pons.

FINNIS, J., 2012: What is the Philosophy of Law?, en Rivista di filosofia del diritto. Journal of Legal Philosophy, 1/2012, 67-77.

GONZÁlEZ VicÉN, F., 1979: Estudios de Filosofía del Derecho, Universidad de La Laguna.

GuAstini, R., 1990: Dalle fonti alle norme, Torino: Giapichelli.

- 2012: «Manifesto di una filosofía analítica del diritto», en Rivista di filosofía del diritto. Journal of Legal Philosophy, 1/2012, 51-65.

PRIETO, L., 2000: «Tribunal Constitucional y positivismo jurídico», en Doxa, núm. 23.

SCARPELLI, U., 1965: Cos ê il positivismo giuridico?, Milano: Edizioni di Comunità. 